\title{
THE EFFECT OF HIP JOINT ANGLE ON ISOMETRIC MID-THIGH PULL
}

\section{KINETICS}

Original Research

Funding Statement: No external funding was received for this work.

Conflict of Interest: There are no conflicts of interest concerning this paper

Thomas Dos'Santos ${ }^{1 \#}$, Christopher Thomas ${ }^{1}$, Paul A Jones ${ }^{1}$, John J McMahon ${ }^{1}$ and Paul

Comfort $^{1}$

${ }^{1}$ Human Performance Laboratory, Directorate of Sport, Exercise, and Physiotherapy,

University of Salford, Greater Manchester, United Kingdom

\#Corresponding Author: Thomas Dos'Santos

Telephone: +447961744517

Email: t.dossantos@edu.salford.ac.uk

Preferred running head: Joint angle and isometric kinetics

Abstract word count: 284 words

Manuscript word count: 4665 words

Number of tables and figures: 3 Tables and 2 Figures 


\section{ABSTRACT}

The aims of this study were to compare isometric mid-thigh pull (IMTP) peak force (PF), time-specific force values (100-, 150- and $200 \mathrm{~ms}$ ), rate of force development (RFD) at predetermined time bands (0-100, 0-150 and 0-200 ms) and net forces between two commonly adopted hip joint angles $\left(145^{\circ}\left[\right.\right.$ hip $\left._{145}\right]$ and $175^{\circ}\left[\right.$ hip $\left.\left._{175}\right]\right)$ with a $145^{\circ}$ standardised knee angle. Twenty-eight collegiate athletes (age: $21.7 \pm 1.5$ years, height: $1.75 \pm 0.08 \mathrm{~m}$, mass: $81.5 \pm$ $8.4 \mathrm{~kg}$ ) performed two IMTP trials at each hip joint angle in a randomised counterbalanced order. A subgroup $(n=10)$ performed the IMTP testing seven days later to establish betweensession reliability. Intraclass correlation coefficients (ICC) and coefficient of variation (CV) demonstrated high within-session reliability and acceptable variability for all IMTP kinetics at each posture (ICC $\geq 0.86, \mathrm{CV} \leq 13.7 \%$ ) excluding hip ${ }_{175} \mathrm{RFD} 0-100 \mathrm{~ms}$ and net force at $100 \mathrm{~ms}$ which demonstrated greater variability $(\mathrm{CV}=18.1-18.5 \%)$. High-between session reliability and acceptable variability were observed for all IMTP kinetics at each posture $(\mathrm{ICC}=0.72-0.97, \mathrm{CV}=4.5-12.8 \%)$, excluding RFD 0-100 ms which demonstrated greater variability for both postures. Hip ${ }_{145}$ produced significantly greater time-specific force values $(\mathrm{p} \leq 0.025, g=0.25-0.28), \mathrm{RFD}$ at pre-determined time bands $(\mathrm{p} \leq 0.001, g=0.59-0.78)$ and net forces $(\mathrm{p} \leq 0.001, g=0.57-0.74)$ compared to hip ${ }_{175}$. Trivial non-significant differences were demonstrated between postures for PF and force at $100 \mathrm{~ms}(\mathrm{p}>0.05, g \leq 0.14)$. Significantly greater body weights (weighing period force) were observed with hip 175 compared to hip $p_{145}(\mathrm{p}<0.001, g=0.74)$. Coaches should consider administering a hip ${ }_{145}$ for IMTP testing as greater IMTP kinetics and lower levels of pre-tension during the weighing period are achieved with this posture.

Key words rate of force development; time-specific force; peak force; net force; assessment 


\section{INTRODUCTION}

The neuromuscular qualities of the lower limb can be evaluated using force-time curves recorded from the isometric mid-thigh pull (IMTP). The IMTP is commonly used to assess the peak force (PF) production but a further advantage is the ability to inspect an athlete's ability to produce force $(4,12,15,22)$, rate of force development (RFD) $(4,12,22)$ and impulse $(8,43)$ at critical time intervals. The IMTP has been shown to demonstrate high within- and between-session reliability measures for PF $(8,11,14,15,22)$, time-specific force values $(4,12,15,22)$, rate of force development $(12,22)$ and impulse $(8,43)$ across different time intervals. Due to the high reliability and its simplicity to administer, the IMTP is commonly used to evaluate the force-time qualities to prescribe future training such as inspection of the dynamic strength index when combined with PF during a jump (45); while also used to monitor adaptations to training (3). Additionally, the IMTP can be used as a potentially safer surrogate to dynamic one repetition maximum (1RM) strength testing (8, 11), with strong correlations observed between IMTP PF and 1RM back squat ( $r \geq 0.96)$ (33, 35), snatch and clean and jerk $(r \geq 0.83)$ (4) and deadlift $(r=0.88)$ (11). Moreover, inspecting neuromuscular preparedness (18) and assessment of bilateral (1) and unilateral force production asymmetries (13) are further purposes of IMTP testing.

The IMTP is modelled on the start of the second pull position of the clean whereby the largest forces, velocities and power are generated $(17,23)$. However, a contentious issue in IMTP testing is the selection of appropriate knee and hip joint angles. Currently there is no agreed consensus on the appropriate knee and hip joint angles for IMTP testing. The IMTP was first introduced by Haff et al. (23) where knee and hip angles of $144 \pm 5^{\circ}$ and $145 \pm 3^{\circ}$ were reported, respectively. Since then, a diverse spectrum of knee angles (120-145 $)$ have been reported including fixed specific angles of $130^{\circ}(33,34)$ and $140^{\circ}(9,36,38)$, while some researchers report a range of knee angles adopted by subjects including $120-130^{\circ}(10$, 
$46), 125 \pm 5^{\circ}(1), 125-135^{\circ}(4), 127-145^{\circ}(20,21,28), 137.6 \pm 12.9^{\circ}(22), 141 \pm 10(27)$ and $140-145^{\circ}$ (40). Similarly, a wider range of hip joint angles have been reported within the literature ranging from flexed positions of $124 \pm 11^{\circ}$, resulting in a clear forward lean of the trunk, upright positions of $140-145^{\circ}(8,22,38,40)$ and more extended positions of $155-165^{\circ}$ (39) and $170-175^{\circ}(1,4,29,42,47)$. As such, these different knee and hip angles result in different body positions relative to the bar which could impact the force production capabilities during IMTP testing (Figure 1) $(5,6)$.

**Insert Figure 1 about here**

Notably a large contingent of studies do not report their knee $(12,13,30,41,43,45)$ or hip joint angles $(12,13,20,21,28,30,33,34,36,37,44,45)$ for IMTP testing and simply describe the body positioning. For example, researchers have stated self-preferred position $(12,13,43,45)$, bar position below crease of hip (36), bar position at height of knee (30) (which is clearly not a mid-thigh pull, or the start of the second pull during a clean), upright trunk (10), near vertical trunk (40), shoulders placed over the bar (37) and flat trunk with shoulders in line with bar (46). Failure to provide hip and joint angles for IMTP testing makes determining and replicating IMTP protocols difficult. The inconsistences in postures reported within the literature and failure to provide knee and joint angle data could result in discrepancies between studies; in particular the reliability and range of correlations with dynamic performance. Interestingly, some knee joint angles $\left(127-145^{\circ}\right)$ for IMTP testing were calculated during 2-dimensional analysis of each subject's actual weightlifting performance $(20,21)$, but hip joint angles were not provided. This method would require athletes firstly to be competent at the clean and would require extensive periods of time to collect and analyse such data, and would therefore be too time consuming and impractical for testing large squads of athletes and cohorts of subjects. 
Differences in joint angles can impact force production due to changes in the length tension relationship in skeletal muscle, while the force produced acts through different moment arms (48). Consequently, this can influence the contractile properties influencing force $(5,6,32)$ and RFD (32) production during isometric testing. Marcora and Miller (32) reported differences in PF and maximum RFD during the isometric leg press between knee angles $120^{\circ}$ and $90^{\circ}$, respectively. Similarly, Beckham et al. (5) compared isometric PF in key positions of the conventional deadlift (floor, knee, mid-thigh pull, lockout) revealing the midthigh pull position (knee angle $125^{\circ}$, hip angle $145^{\circ}$ ) generated the highest $\mathrm{PF}$, significantly higher than any other position. However, the authors failed to provide the knee and hip joint angles of the lockout position, thus it is uncertain whether the hip and joint angles adopted for the lockout position were reflective of commonly adopted IMTP hip and knee joint angles reported within the literature.

There is a paucity of research comparing IMTP kinetics between different knee and hip joint angles. Comfort et al. (8) compared IMTP kinetics between commonly reported knee $\left(120^{\circ}\right.$, $130^{\circ}, 140^{\circ}$, and $\left.150^{\circ}\right)$ and hip angles $\left(125^{\circ}\right.$ and $\left.145^{\circ}\right)$ and self-preferred posture reporting no meaningful or significant differences $(p>0.05, d \leq 0.061)$ in PF, maximal RFD or impulse at 100-, 200- and $300 \mathrm{~ms}$ across postures. Additionally, high between session-reliability was observed for all kinetic variables irrespective of posture. The authors advocated the use of a self-preferred mid-thigh pull position for IMTP testing due the high reliability and lack of differences with the other postures, with also the potential ability to speed up IMTP testing to a reduced learning effect. Contrary to the findings of Comfort et al. (8), Beckham et al. (6) has advocated a hip joint angle of approximately $145^{\circ}$ for IMTP testing, reporting greater IMTP kinetics ( $\mathrm{PF}$ and time-specific force values) compared to a flexed $125^{\circ}$ hip joint angle (standardized $125^{\circ}$ knee joint angle) with small to large effect sizes in athletes with weightlifting experience and small to moderate effect sizes without weightlifting experience. 
As such, given the conflicting findings from these two studies, there is no consensus on the optimal joint angle for IMTP testing.

There is a requirement therefore, for further investigations into the effects of different joint angles on IMTP kinetics; specifically comparing the commonly reported and adopted hip angles of $145^{\circ}(8,22,23,38,40)$ and $175^{\circ}(1,4,29,42,47)$ within the literature; which Comfort et al. (8) and Beckham et al. (6) did not investigate. These two hip angles result in different body positions relative to the bar which could potentially effect force production during IMTP testing (Figure 1). Practitioners use the IMTP to assess the rapid force production properties of their athletes, thus it is imperative that athletes adopt the most optimal and favourable position (joint angle) to rapidly produce force. Subsequently, the results from this study should provide greater insight into which positions are favourable and optimal for isometric rapid force production. Thus, the aims of this study were to compare IMTP PF, time-specific force values, RFD at pre-determined time bands and net forces between two different hip joint angles $\left(145^{\circ}\right.$ and $\left.175^{\circ}\right)$ with a standardised knee angle of $145^{\circ}$. It was hypothesised that greater IMTP kinetics would be observed with a $145^{\circ}$ hip joint angle compared to a $175^{\circ}$ angle, due to advantageous length tension relationships of the hip extensors.

\section{METHODS}

\section{Experimental approach to the problem}

A repeated measures, within-subjects design was used to evaluate the effects of hip joint angle $\left(145^{\circ}\right.$ vs $\left.175^{\circ}\right)$ at a standardised knee joint angle $\left(145^{\circ}\right)$ on IMTP PF, time-specific force values, RFD at pre-determined time bands and net forces. A randomised and counterbalanced testing protocol was used to control for order effect whereby subjects performed two maximum effort IMTPs in each position while standing on a force plate 
sampling at $1000 \mathrm{~Hz}$. IMTP testing was performed on two separate testing sessions seven days apart at the aforementioned postures to determine the within-session and betweensession reliability of each measure and to determine the effect of hip joint angles on the dependent variables (PF, time-specific force values, RFD at pre-determined time bands and net forces).

\section{$\underline{\text { Subjects }}$}

Twenty-eight (23 male and 5 female) collegiate athletes (age: $21.7 \pm 1.5$ years, height: $1.75 \pm$ $0.08 \mathrm{~m}$, mass: $81.5 \pm 8.4 \mathrm{~kg}$, relative one repetition maximum power clean: $1.06 \pm 0.18$ $\mathrm{kg} / \mathrm{BM})$ from rowing and soccer participated in this study. A subgroup $(\mathrm{n}=10)$ returned on a second occasion seven days later at the same time of day to determine between-session reliability. Based on the work of Beckham et al. (5) for differences in isometric PF between postures, a minimum sample size of 15 was determined from an a priori power analysis using G*Power (Version 3.1, University of Dusseldorf, Germany) (16) based upon an effect size of 1.23, a power of 0.99 and type 1 error or alpha level of 0.05 .

The investigation was approyed by the institutional ethics review board, and all subjects were informed of the benefits and risks of the investigation prior to signing an institutionally approved consent form to participate in the study. Subjects were familiar with the IMTP protocol and had $\geq 6$ months resistance training experience of the power clean and its' derivatives; all IMTP trials were assessed by certified strength and conditioning specialists. At the time of testing subjects were mid-season in the first week of a power mesocycle having performed a four-week maximum strength mesocycle. 


\section{$\underline{\text { Procedures }}$}

All testing took place at the same time of day and a subgroup $(n=10)$ returned on a second occasion seven days later at the same time of day to minimize the effect of circadian rhythm and to determine between-session reliability. Subjects were required to abstain from training for $48 \mathrm{~h}$ before testing and asked to maintain a consistent fluid and dietary intake on each day of testing.

\section{Pre-isometric assessment warm up}

All subjects performed a standardized warm up comprised of ten body weight squats and lunges followed by two isometric efforts at a perceived intensity of 50, and $75 \%$ of maximum effort, interspersed with a one-minute rest period $(5,29)$.

\section{$\underline{\text { Isometric mid-thigh pull protocol }}$}

The IMTP testing was performed on a portable force plate sampling at $1000 \mathrm{~Hz}$ (Kistler, Winterthur, Switzerland, Model 9286AA, SN 1209740) using a portable IMTP rack (Fitness Technology, Adelaide, Australia. Sampling at $1000 \mathrm{~Hz}$ has been shown to produce high reliability for isometric force-time variables (12). A cold rolled steel bar was positioned to correspond to the athlete's second-pull power clean position where the bar height could be adjusted ( $3 \mathrm{~cm}$ increments) at various heights above the force plate to accommodate different sized athletes. Athletes were strapped to the bar in accordance to previous research (20) and positioned in two different postures; both postures required a standardised knee joint angle of $145^{\circ}$ however required different hip joint angles of $145^{\circ}\left(\operatorname{Hip}_{145}\right)$ and $175^{\circ}\left(\operatorname{Hip}_{175}\right)$, respectively. Subjects were placed in position; knee and hip relative angles (angle between two segments) were measured with goniometry to ensure that the position was accurately reproduced during each trial, with the bar resting midway up the thigh (approximately 
halfway between the iliac crest and the midpoint of the patella), just below the inguinal crease of the hip, to replicate the start position of the second pull phase of the clean. Hip H45 $_{145}$ positioning resulted in a posture with shoulders directly above or slightly behind the bar, conversely Hip ${ }_{175}$ resulted in a posture with shoulders noticeably behind the bar as illustrated in Figure 1.

All subjects received standardized instructions to pull as fast and as hard as possible and push their feet directly into the force plate until being told to stop, as these instructions have been shown to produce optimal results (7). Once the body was stabilised (verified by watching the subject and force trace) the IMTP was initiated with the countdown " $3,2,1$ pull," with subjects ensuring that maximal effort was applied for five seconds. Ground reaction force data were collected for a duration of eight seconds from the portable force platform which was interfaced with a laptop and recorded using Bioware software (Version 5.11; Kistler Instrument Corporation, Winterthur, Switzerland). Minimal pre-tension was allowed to ensure there was no slack in the body prior to initiation of pull and subjects were instructed to be as still as possible during the weighing period, without initiating a pull on the bar, until given the instructions to 'pull'. Trials without a stable baseline force trace (change in force > $50 \mathrm{~N}$ ) were rejected along with trials with a visible countermovements, subsequently another trial was performed $(14,31)$. Subjects performed a total of two maximal effort trials at each hip joint angle in a randomised and counterbalanced order, with each trial and interspersed with a 2-minute rest period. Strong verbal encouragement was given for all trials and subjects. In line with previous recommendations, if the difference between the two trials exceeded $250 \mathrm{~N}$ then a third trial was performed $(4,29)$. The mean of two trials were used for statistical analyses. 


\section{$\underline{\text { Isometric force-time curve assessment }}$}

All force-time data recorded during the IMTP were inspected using a customized analysis Microsoft Excel spreadsheet (version 2016, Microsoft Corp., Redmond, WA, USA) to determine specific force-time characteristics. The maximum force generated during the five second maximum effort IMTP was reported as the absolute PF (22). Additionally, timespecific force values at $100 \mathrm{~ms}\left(\right.$ Force $\left._{100}\right), 150 \mathrm{~ms}\left(\right.$ Force $\left._{150}\right)$ and $200 \mathrm{~ms}\left(\right.$ Force $\left._{200}\right)$ were calculated $(12,22)$. Net PF and net time-specific force values were calculated by subtracting BW (calculated during 1 second weighing period) from the time-specific force value. RFD at pre-determined time bands 0-100, 0-150 and 0-200 ms $\left(\mathrm{RFD}_{100}, \mathrm{RFD}_{150}\right.$ and $\left.\mathrm{RFD}_{200}\right)$ were also calculated using the equation: $\mathrm{RFD}=\Delta$ force/ $\Delta$ time interval $(4,12,22,29)$. The onset of the contraction was determined when vertical ground-reaction force deviated 5 SD of BW (14). The combined residual force and BW/were calculated as the average force over a 1 second stationary weighing period (in mid-thigh pull position posture) prior to the initiation of the IMTP (14).

\section{$\underline{\text { Statistical analyses }}$}

Statistical analyses were performed using SPSS software version 23 (SPSS, Chicago, Ill, USA). Normality for all variables was confirmed using a Shapiro Wilks-test. Within-session reliability and between-session reliability were assessed via intraclass correlation coefficients (ICC), $95 \%$ confidence intervals (CI), coefficient of variation (CV) calculated as SD/mean $\mathrm{x}$ 100 and standard error of measurement (SEM). Minimum acceptable reliability was determined with an ICC $>0.7$ and $\mathrm{CV}<15 \%(2,22)$. 
Paired sample t tests and effect sizes were used to compare IMTP kinetics between sessions.

Differences in IMTP kinetics between postures were assessed using paired sample t tests, effect sizes, mean differences and percentage differences. Effect sizes were calculated using Hedges' $g$ method (24) and interpreted using Hopkins' scale (25). The criterion for significance was set at $p \leq 0.05$.

\section{RESULTS}

High within-session reliability was observed for hip ${ }_{145} \mathrm{IMTP} P F(\mathrm{ICC}=0.99, \mathrm{CV}=2.8 \%)$, time-specific force values $(\mathrm{ICC}=0.92-0.98, \mathrm{CV}=3.5-6.2 \%), \mathrm{RFD}$ at pre-determined time bands $(\mathrm{ICC}=0.91-0.97, \mathrm{CV}=5.9-12.1 \%)$ and net forces $(\mathrm{ICC}=0.91-0.98, \mathrm{CV}=4.6-$ $11.6 \%$ ); all achieving minimum acceptable reliability criteria (Table 1). With the exception of $\operatorname{hip}_{175} \mathrm{RFD}_{100}$ and net force ${ }_{100}$ which failed to meet minimum acceptable reliability criteria, high within-session reliability was observed for hip ${ }_{175}$ IMTP PF $($ ICC $=0.99$, CV $=2.8 \%)$, time specific force values $(\mathrm{ICC}=0.93-0.98, \mathrm{CV}=2.9-5.8 \%), \mathrm{RFD}$ at pre-determined time bands $(\mathrm{ICC}=0.86-0.96, \mathrm{CV}=8.4-13.3 \%)$ and net forces $(\mathrm{ICC}=0.83-0.97, \mathrm{CV}=5.3-13.7 \%)$ (Table 1). Body weight was highly reliable, irrespective of posture $(\mathrm{ICC}=0.93-0.95, \mathrm{CV}=$ $3.5-5.0 \%)$ (Table 1).

$$
\text { ***Insert Table } 1 \text { about here*** }
$$

Between-session testing demonstrated high reliability for all kinetics across both postures $(\mathrm{ICC}=0.72-0.97, \mathrm{CV}=4.5-12.8 \%)$ with the exception of $\mathrm{RFD}_{100}$ which failed to achieve minimum acceptable reliability criteria for both postures (Table 2). Significant differences 
between sessions were observed only for hip ${ }_{145} \mathrm{PF}(\mathrm{p}=0.033)$ and net $\mathrm{PF}(\mathrm{p}=0.05)$ with effect sizes revealing a small difference $(g=0.21-0.23)$. No other significant differences $(\mathrm{p}>0.05, \mathrm{~g}$ $\leq 0.22$ ) were observed between sessions for all IMTP kinetics across both postures (Table 2).

***Insert Table 2 about here***

IMTP descriptive statistics between postures are presented in Table 3 along with p values, effect sizes, mean and percentage differences. Trivial non-significant differences were demonstrated between postures for PF and force ${ }_{100}(\mathrm{p}>0.05, g \leq 0.14)$. However, hip $\mathrm{p}_{145}$ produced significantly greater time-specific force values $(\mathrm{p} \leq 0.025, g=0.25-0.28)$, RFD at pre-determined time bands $(\mathrm{p} \leq 0.001, g=0.59-0.78)$ and net forces $(\mathrm{p} \leq 0.001, g=0.57$ 0.74) in comparison to hip 175 , with effect sizes indicating small to moderate differences (Table 3). Conversely, significantly higher BW $(\mathrm{p}<0.001)$ was observed with a hip 175 angle compared to hip 145 , with a moderate effect size $(g=0.74)$ (Table 3$)$.

\section{DISCUSSION}

The aims of the present study were to compare IMTP kinetics between commonly reported hip joint angles $145^{\circ}$ and $175^{\circ}$ with a standardized knee joint angle. This study is the first to compare a hip ${ }_{175}$ joint angle to a hip 145 joint angle finding significantly greater time-specific force values, RFD at pre-determined time bands and net forces with a hip 145 posture compared to a more extended hip 175 posture (Table 3 ); in agreement with our hypotheses. 
Equally, both postures resulted in high within-session and between-session reliability measures for all IMTP kinetics, with the exception of $\mathrm{RFD}_{100}$ which failed to meet minimum acceptable reliability for both postures between-sessions (Table $1 \& 2$ ). Consequently, the results from this study suggest a $145^{\circ}$ hip angle is a more favourable position for rapid force production compared to a more extended hip position $\left(175^{\circ}\right)$ during IMTP testing. Therefore, practitioners should consider administering IMTP testing with an approximate $145^{\circ}$ relative hip joint angle compared to a $175^{\circ}$ hip joint angle, while also acknowledging that adopting different and inconsistent joint angles can significantly influence IMTP kinetics.

A diverse range of hip and knee joint angles have been reported within the literature for IMTP testing $(1,4,22,23,38,39,42,47)$. To our knowledge, Comfort et al. (8) and Beckham et al. (6) are the only studies to examine the effect of joint angle on a range of IMTP kinetics reporting conflicting findings. Comfort et al. (8) demonstrated no significant or meaningful differences $(p>0.05, d \leq 0.061)$ for PF, maximum RFD and impulse at 100-, 200- and $300 \mathrm{~ms}$ between joint angles and the authors advocated the use of a self-preferred mid-thigh pull position to minimise the learning effect. Conversely, Beckham et al. (6) found greater peak force and time-specific force values (small to large effect sizes) were achieved with a hip joint angle of $145^{\circ}$ compared to a more flexed $125^{\circ}$ angle. The present study compared a hip 145 joint angle to an extended hip 175 joint angle reporting no significant differences in $\mathrm{PF}$ between postures, but small to moderate significant differences in time specific-force values, RFD at pre-determined time bands and net forces were observed between postures (Table 3). Notably, greater mean and percentage differences were observed for net forces and RFD variables (Table 3) between postures indicating a greater influence on these kinetic variables. As such, the results from the present study are in agreement with Beckham et al. (6) highlighting that hip joint angle and subsequent body position influences isometric rapid force production. Supporting the recommendations of Beckham et al. (6) we 
recommend coaches and researchers should consider administering an approximate $145^{\circ}$ hip joint angle for IMTP testing.

The data from the present study shows that a hip ${ }_{145}$ position appears to be a favourable position to assess the rapid force production capabilities of athletes while also demonstrating that hip joint angle directly influences time specific-force, net force and RFD characteristics (Table 3). This is supported by previous studies who have shown differences in maximum RFD and PF between $90^{\circ}$ and $120^{\circ}$ knee flexion during the isometric leg press (32). Beckham et al. (5) also observed significant differences in PF between various positions in the deadlift and the mid-thigh pull position. Interestingly, the authors compared a mid-thigh pull position to a deadlift lockout position demonstrating large differences in $\mathrm{PF}(d=1.23)$; however, $\mathrm{PF}$ was the only kinetic variable examined and the specific joint angles of the lockout position were not provided. Nonetheless, based on the results of this study and corroborative research, lower limb joint angle influences force production during isometric testing $(5,6,32)$. As such, coaches and researchers should ensure joint angles are standardised and consistent between testing occasions to allow valid comparisons of performance variables when longitudinally monitoring neuromuscular performance, so such changes in IMTP kinetics can be attributed to training or fatigue, and not to differences in joint angles.

Coaches use the IMTP to assess the rapid force production properties of their athletes to monitor and inform future training, thus it is imperative that athletes adopt the most optimal and favourable position (joint angle) to rapidly produce force. The results of the present study demonstrate an extended hip joint angle of $175^{\circ}$ was a suboptimal position for force production compared to hip pis $_{15}$ joint angle (Table 3), while Beckham et al. (6) observed a flexed $125^{\circ}$ hip joint angle was also suboptimal in force production compared to hip 145 . Collectively, the results of these studies suggest that body position relative to the bar does matter for IMTP force production. Failure to place athletes in the optimal joint angles (body 
position) of hip ${ }_{145}$ could limit rapid force production, potentially leading to misinterpretations of their force production capabilities.

A stable baseline force during the weighing period with minimal pre-tension before the onset of a rapid contraction is recommended when conducting isometric testing (31). Interestingly, considerably greater BW (weighing period forces) was observed for the hip 175 posture compared to the hip ${ }_{145}$ (Table 3). This indicates higher levels of pre-tension were achieved with the hip ${ }_{175}$ posture which is suboptimal for evaluating RFD during isometric testing (31); and should therefore be avoided for IMTP testing.

Notably, significantly greater RFD at pre-determined time bands were demonstrated with a hip $_{145}$ posture compared to hip ${ }_{175}$, with mean percentage differences ranging from $16.8-21.1 \%$ (Table 3). As RFD was calculated as $=\Delta$ force/ $\Delta$ time interval the consistently greater RFD may be explained by several factors including, the significantly greater net forces and lower BW (weighing period forces), which has a direct effect on the change in force component of the RFD equation. Additionally, significantly greater force ${ }_{150}$ and force 200 values were observed with a hip ${ }_{145}$ joint angle, directly influencing RFD. Collectively the abovementioned factors such as lower BW (weighing period force to determine the onset of contraction - due to lower pre-tension), greater net forces and time-specific forces results in a greater change in force, thus greater RFD with a hip 145 joint angle. Thus, practitioners are recommended to administer IMTP testing with a hip 145 joint angle for a more favourable position to attain RFD, time-specific force values and net force data.

Numerous investigations have adopted hip joint angles of approximately $170-175^{\circ}$ during IMTP testing $(1,4,29,42,47)$; however, interpretation of these aforementioned studies may be limited, because the results of the present study indicate higher levels of pre-tension, lower RFD, lower time-specific forces, lower net forces, and lower reliability measures are 
achieved with the hip ${ }_{175}$ posture (Tables 1-3). This posture appears to be a suboptimal position for producing force and RFD compared to hip ${ }_{145}$, potentially due to differences in length tension relationship of the hip extensors and differences in moment arms (48). We suggest that that the hip joint angles reported by the aforementioned studies $(1,4,29,42,47)$ may be misrepresented and we question whether the authors are potentially referring absolute hip or trunk angle relative to a vertical straight line in comparison to measuring relative joint angle (angle between two segments meeting at a point) as done in the present study (19) (Figure 2). Figure 2 illustrates the notable differences in trunk position relative to the bar between absolute and relative hip 175 joint angles. Therefore, coaches and researchers are advised to specify and standardise their knee and hip joint angles adopted for IMTP testing and state whether absolute or relative joint angles were measured to avoid confusion and allow the replication of IMTP testing methodologies.

\section{**Insert Figure 2 about here**}

The present study found PF to demonstrate the highest between-session reliability measures for both postures (Table 2) similar to the observations of previous between-session (ICC $\geq$ $0.89, \mathrm{CV} \leq 4.6 \%)(8,11,15,45)$ and within-session research $(\mathrm{ICC} \geq 0.97, \mathrm{CV} \leq 3.2 \%)(12$ 22). Equally, both postures demonstrated high levels of within-session reliability for timespecific force values (Table 1) comparable to the reliability measures reported in previous research $(4,12,22,29)$. Limited studies have inspected the between-session reliability of time-specific force values $(15,26)$. High and acceptable between-session reliability measures were demonstrated for all time-specific force values (Table 2) in accordance with the reliability measures reported in youth male soccer players (15) and higher than the measures reported by James et al. (26). The results from this study confirm that both postures produce 
equally high within-session and between-session reliability measures for PF and time-specific force values.

Haff et al. (22) has shown that the method to quantify RFD can influence the resultant value and reliability of such measures, and as such, using pre-determined time bands to calculate RFD has been recommended. To our knowledge only one other study (26) has assessed the between session reliability of RFD at pre-determined time bands. RFD $_{100}$ in the present exceeded minimum acceptable reliability criteria at both postures (between-sessions) similar to the results of previous research (26). Conversely, lower and acceptable levels of variance were demonstrated for $\mathrm{RFD}_{150}$ and $\mathrm{RFD}_{200}$ consistent with the results of James et al. (26) who also showed improved RFD reliability measures over longer time intervals. High and acceptable within-session reliability measures were observed for all RFD variables during hip 145 testing however $\mathrm{RFD}_{100}$ and net force ${ }_{100}$ exceeded minimum acceptable reliability at hip $_{175}$ posture (Table 1). Therefore, the results from this study confirm that a hip ${ }_{145}$ posture produces high-within session reliability for all RFD variables however both postures result in unacceptable reliability for $\mathrm{RFD}_{100}$ (Table $1 \& 2$ ).

It should be acknowledged the present study only examined the effect of two different hip joint angles $\left(145^{\circ}\right.$ and $\left.175^{\circ}\right)$ on IMTP kinetics, while Beckham et al. (6) only compared two hip joint angles $\left(145^{\circ}\right.$ and $\left.125^{\circ}\right)$ as well. Comfort et al. (8) recommends the use of a selfpreferred selection of knee and hip joint angles as reporting no significant differences between self-preferred position and a range of knee $\left(120^{\circ}, 130^{\circ}, 140^{\circ}\right.$, and $\left.150^{\circ}\right)$ and hip joint angles. The present study and Beckham et al. (6) both demonstrated greater force production with a hip ${ }_{145}$ but did not compare this to a self-preferred position. Therefore, further research is required comparing hip ${ }_{145}$ joint angle to self-preferred position to determine which body position results in optimal force production. 


\section{PRACTICAL APPLICATIONS}

Coaches and researchers should conduct IMTP testing with a $145^{\circ}$ hip joint angle due to the greater IMTP kinetics and lower levels of pre-tension observed in this position compared to a $175^{\circ}$ hip joint angle. As such, coaches and researchers should ensure that joint angles are standardised and kept consistent between testing occasions to allow valid comparisons of performance variables when longitudinally monitoring neuromuscular performance, so such changes in IMTP kinetics can be attributed to training or fatigue, and not to differences in joint angles. Furthermore, researchers are recommended when publishing research to report the knee and hip joint angles adopted for IMTP testing due to the effect on IMTP kinetics and reliability; while specifying if relative or absolute joint angles were measured.

\section{ACKNOWLEDGMENTS}

The authors would like to thank the individuals who participated in this investigation. No grant funding was received to support this research and the authors have no conflict of interest.

\section{REFERENCES}

1. Bailey C, Sato K, Alexander R, Chiang C-Y, and Stone MH. Isometric force production symmetry and jumping performance in collegiate athletes. Journal of Trainology 2: 1-5, 2013.

2. Baumgartner TA and Chung H. Confidence limits for intraclass reliability coefficients. Meas Phys Educ Exerc Sci 5: 179-188, 2001.

3. Beattie K, Carson BP, Lyons M, and Kenny IC. The Effect of Maximal-\& Explosive-Strength Training on Performance Indicators in Cyclists. International journal of sports physiology and performance: Published Ahead of Print, 2016.

4. Beckham G, Mizuguchi S, Carter C, Sato K, Ramsey M, Lamont H, Hornsby G, Haff G, and Stone M. Relationships of isometric mid-thigh pull variables to weightlifting performance. J Sports Med Phys Fitness 53: 573-581, 2013.

5. Beckham G, S. Lamont H, Sato K, W. Ramsey M, and H. Stone M. Isometric strength of powerlifters in key positions of the conventional deadlift. Journal of Trainology 1: 32-35, 2012. 
6. Beckham GK, Sato K, Mizuguchi S, Haff GG, and Stone MH. Effect of Body Position on Force Production During the Isometric Mid-Thigh Pull. The Journal of Strength \& Conditioning Research: Published Ahead of Print, 2017.

7. Bemben MG, Clasey JL, and Massey BH. The effect of the rate of muscle contraction on the force-time curve parameters of male and female subjects. Research quarterly for exercise and sport 61: 96-99, 1990.

8. Comfort P, Jones PA, McMahon JJ, and Newton R. Effect of Knee and Trunk Angle on Kinetic Variables During the Isometric Mid-Thigh Pull: Test-Retest Reliability. Int J Sports Physiol and Perform 10: 58-63, 2015.

9. Cormie P, McCaulley GO, Triplett NT, and Mcbride JM. Optimal loading for maximal power output during lower-body resistance exercises. Medicine and science in sports and exercise 39: 340, 2007.

10. Darrall-Jones JD, Jones B, and Till K. Anthropometric and physical profiles of English academy rugby union players. The Journal of Strength \& Conditioning Research 29: 2086-2096, 2015.

11. De Witt JK, English KL, Crowell JB, Kalogera KL, Guilliams ME, Nieschwitz BE, Hanson AM, and Ploutz-Snyder LL. Isometric Mid-Thigh Pull Reliability and Relationship to Deadlift 1RM. The Journal of Strength \& Conditioning Research: Published Ahead of Print, 2016.

12. Dos' Santos T, Jones PA, Kelly J, McMahon JJ, Comfort P, and Thomas C. Effect of Sampling Frequency on Isometric Mid-Thigh Pull Kinetics. Int J Sports Physiol and Perform 11: 255-260, 2016.

13. Dos'Santos T, Thomas C, Jones PA, and Comfort P. Assessing muscle strength asymmetry via a unilateral stance isometric mid-thigh pull. International journal of sports physiology and performance: Published Ahead of Print, 2016.

14. Dos'Santos T, Jones PA, Comfort P, and Thomas C. Effect of Different Onset Thresholds on Isometric Mid-Thigh Pull Force-Time Variables. The Journal of Strength \& Conditioning Research: Published Ahead of Print, 2017.

15. Dos'Santos T, Thomas C, Comfort P, McMahon JJ, Jones PA, Oakley NP, and Young AL. Between-Session Reliability Of Isometric Mid-Thigh Pull Kinetics And Maximal Power Clean Performance In Male Youth Soccer Players. The Journal of Strength \& Conditioning Research, 2017.

16. Faul F, Erdfelder E, Buchner A, and Lang A-G. Statistical power analyses using G* Power 3.1: Tests for correlation and regression analyses. Behav Res Methods 41: 1149-1160, 2009.

17. Garhammer J. A Review of Power Output Studies of Olympic and Powerlifting: Methodology, Performance Prediction, and Evaluation Tests. The Journal of Strength \& Conditioning Research 7: 76-89, 1993.

18. Gescheit DT, Cormack SJ, Reid M, and Duffield R. Consecutive Days of Prolonged Tennis Match Play: Performance, Physical, and Perceptual Responses in Trained Players. International Journal of Sports Physiology \& Performance 10, 2015.

19. Grimshaw P, Fowler N, Lees A, and Burden A. BIOS instant notes in sport and exercise biomechanics. Garland Science, 2004.

20. Haff GG, Carlock JM, Hartman MJ, Kilgore JL, Kawamori N, Jackson JR, Morris RT, Sands WA, and Stone MH. Force--Time Curve Characteristics of Dynamic and Isometric Muscle Actions of Elite Women Olympic Weightlifters. J Strength Cond Res 19: 741-748, 2005.

21. Haff GG, Jackson JR, Kawamori N, Carlock JM, Hartman MJ, Kilgore JL, Morris RT, Ramsey MW, Sands WA, and Stone MH. Force-time curve characteristics and hormonal alterations during an eleven-week training period in elite women weightlifters. J Strength Cond Res 22: 433-446, 2008.

22. Haff GG, Ruben RP, Lider J, Twine C, and Cormie P. A comparison of methods for determining the rate of force development during isometric midthigh clean pulls. The Journal of Strength \& Conditioning Research 29: 386-395, 2015. 
23. Haff GG, Stone M, O'Bryant HS, Harman E, Dinan C, Johnson R, and Han K-H. Force-time dependent characteristics of dynamic and isometric muscle actions. J Strength Cond Res 11: 269-272, 1997.

24. Hedges L and Olkin I. Statistical Methods for Meta-Analysis. New York: Acdemic Press, 1985.

25. Hopkins WG. A scale of magnitudes for effect statistics. A new view of statistics, 2002.

26. James LP, Roberts LA, Haff GG, Kelly VG, and Beckman EM. The validity and reliability of a portable isometric mid-thigh clean pull. J Strength Cond Res, 2015.

27. Kawamori N, Rossi SJ, Justice BD, Haff EE, Pistilli EE, O'Bryant HS, Stone MH, and Haff GG. Peak force and rate of force development during isometric and dynamic mid-thigh clean pulls performed at various intensities. J Strength Cond Res 20: 483-491, 2006.

28. Khamoui AV, Brown LE, Nguyen D, Uribe BP, Coburn JW, Noffal GJ, and Tran T. Relationship between force-time and velocity-time characteristics of dynamic and isometric muscle actions. J Strength Cond Res 25: 198-204, 2011.

29. Kraska JM, Ramsey MW, Haff GG, Fethke N, Sands WA, Stone ME, and Stone MH. Relationship between strength characteristics and unweighted and weighted vertical jump height. Int J Sports Physiol Perform 4: 461-473, 2009.

30. Lawton TW, Cronin JB, and Mcguigan MR. Anthropometry, strength and benchmarks for development: A basis for junior rowers' selection? Journal of sports sciences 30: 995-1001, 2012.

31. Maffiuletti NA, Aagaard P, Blazevich AJ, Folland J, Tillin N, and Duchateau J. Rate of force development: physiological and methodological considerations. European journal of applied physiology: 1-26, 2016.

32. Marcora S and Miller MK. The effect of knee angle on the external validity of isometric measures of lower body neuromuscular function. Journal of sports sciences 18: 313-319, 2000.

33. McGuigan MR, Newton MJ, Winchester JB, and Nelson AG. Relationship between isometric and dynamic strength in recreationally trained men. J Strength Cond Res 24: 2570-2573, 2010.

34. McGuigan MR and Winchester JB. The relationship between isometric and dynamic strength in college football players. J Sports Sci Med 7: 101, 2008.

35. McGuigan MR, Winchester JB, and Erickson T. The importance of isometric maximum strength in college wrestlers. I Sports Sci Med 5: 108-113, 2006.

36. Nuzzo JL, McBride JM, Cormie P, and McCaulley GO. Relationship between countermovement jump performance and multijoint isometric and dynamic tests of strength. J Strength Cond Res 22: 699-707, 2008.

37. Secomb JL, Lundgren LE, Farley OR, Tran TT, Nimphius S, and Sheppard JM. Relationships between lower-body muscle structure and lower-body strength, power, and muscle-tendon complex stiffness. The Journal of Strength \& Conditioning Research 29: 2221-2228, 2015.

38. Spiteri T, Nimphius S, Hart NH, Specos C, Sheppard JM, and Newton RU. The contribution of strength characteristics to change of direction and agility performance in female basketball athletes / Strength Cond Res 28: 2415-2423, 2014.

39. Stone MH, Sanborn K, O'Bryant HS, Hartman M, Stone ME, Proulx C, Ward B, and Hruby J. Maximum strength-power-performance relationships in collegiate throwers. J Strength Cond Res 17: 739-745, 2003.

40. Stone MH, Sands WA, Carlock JON, Callan SAM, Dickie DES, Daigle K, Cotton J, Smith SL, and Hartman $M$. The importance of isometric maximum strength and peak rate-of-force development in sprint cycling. J Strength Cond Res 18: 878-884, 2004.

41. Stone MH, Sands WA, Pierce KC, Carlock JON, Cardinale M, and Newton RU. Relationship of maximum strength to weightlifting performance. Med Sci Sports Exerc 37: 1037-1043, 2005. 
42. Stone MH, Sands WA, Pierce KC, Ramsey MW, and Haff GG. Power and power potentiation among strength-power athletes: preliminary study. International journal of sports physiology and performance 3: 55-67, 2008.

43. Thomas $C$, Comfort $P$, Chiang $C-Y$, and Jones $P$. Relationship between isometric mid-thigh pull variables and sprint and change of direction performance in collegiate athletes. Journal of Trainology 4: 6-10, 2015.

44. Thomas C, Dos'Santos T, Comfort P, and Jones PA. Relationship between Isometric Strength, Sprint, and Change of Direction Speed in Male Academy Cricketers. Journal of Trainology 5 : 18-23, 2016.

45. Thomas C, Jones PA, and Comfort P. Reliability of the Dynamic Strength Index in Collegiate Athletes. Int J Sports Physiol and Perform 10: 542 -545, 2015.

46. West DJ, Owen NJ, Jones MR, Bracken RM, Cook CJ, Cunningham DJ, Shearer DA, Finn CV, Newton RU, and Crewther BT. Relationships between force time characteristics of the isometric midthigh pull and dynamic performance in professional rugby league players. $\mathrm{J}$ Strength Cond Res 25: 3070-3075, 2011.

47. Whittington J, Schoen E, Labounty L, Hamdy R, Ramsey M, Stone M, Sands W, Haff G, and Stone M. Bone mineral density and content of collegiate throwers: influence of maximum strength. Journal of Sports Medicine and Physical Fitness 49: 464, 2009.

48. Zatsiorsky VM and Kraemer WJ. Science and practice of strength training. Human Kinetics, 2006. 
Table 1. Within-session reliability measures of IMTP kinetics across postures

\begin{tabular}{|c|c|c|c|c|c|c|c|c|}
\hline & \multirow{2}{*}{ Variable } & \multirow{2}{*}{ ICC } & \multicolumn{2}{|c|}{$95 \% \mathrm{CI}$} & \multirow[b]{2}{*}{$\mathrm{CV}(\%)$} & \multicolumn{2}{|c|}{$95 \% \mathrm{CI}$} & \multirow{2}{*}{ SEM } \\
\hline & & & LB & UB & & LB & UB & \\
\hline \multirow{12}{*}{ Hip $_{145}$} & $\mathbf{P F}$ & 0.99 & 0.97 & 1.00 & 2.8 & 1.8 & 3.7 & 68.1 \\
\hline & Force $_{100}$ & 0.92 & 0.82 & 0.96 & 6.2 & 4.5 & 7.8 & 92.5 \\
\hline & RFD $_{100}$ & 0.91 & 0.82 & 0.96 & 12.1 & 8.9 & 15.3 & 768.6 \\
\hline & Force $_{150}$ & 0.97 & 0.94 & 0.99 & 4.6 & 3.4 & 5.7 & 72.0 \\
\hline & RFD $_{150}$ & 0.97 & 0.93 & 0.98 & 7.5 & 4.9 & 10.1 & 461.5 \\
\hline & Force $_{200}$ & 0.98 & 0.95 & 0.99 & 3.5 & 2.3 & 4.6 & 67.8 \\
\hline & RFD $_{200}$ & 0.95 & 0.90 & 0.98 & 5.9 & 3.5 & 8.2 & 394.6 \\
\hline & Net PF & 0.98 & 0.95 & 0.99 & 4.6 & 3.2 & 6.1 & 87.1 \\
\hline & Net $_{\text {Force }} 100$ & 0.91 & 0.81 & 0.96 & 11.6 & 8.6 & 14.7 & 80.4 \\
\hline & Net Force $_{150}$ & 0.97 & 0.93 & 0.99 & 7.5 & 5.2 & 9.8 & 67.9 \\
\hline & Net Force $_{200}$ & 0.96 & 0.91 & 0.98 & 5.9 & 3.8 & 8.0 & 74.8 \\
\hline & BW & 0.95 & 0.90 & 0.98 & 3.5 & 2.1 & 5.0 & 35.4 \\
\hline \multirow{12}{*}{ Hip $_{175}$} & PF & 0.99 & 0.98 & 1.00 & 2.8 & 2.1 & 3.5 & 66.2 \\
\hline & Force $_{100}$ & 0.93 & 0.82 & 0.97 & 5.8 & 4.1 & 7.4 & 78.7 \\
\hline & RFD $_{100}$ & 0.86 & 0.69 & 0.93 & 18.1 & 10.7 & 25.5 & 778.4 \\
\hline & Force $_{150}$ & 0.95 & 0.88 & 0.98 & 5.3 & 3.9 & 6.8 & 83.5 \\
\hline & RFD $_{150}$ & 0.90 & 0.78 & 0.95 & 13.3 & 8.4 & 18.1 & 2004.3 \\
\hline & Force $_{200}$ & 0.98 & 0.95 & 0.99 & 2.9 & 1.8 & 4.0 & 58.2 \\
\hline & $\mathbf{R F D}_{200}$ & 0.96 & 0.91 & 0.98 & 8.4 & 5.9 & 10.8 & 345.7 \\
\hline & Net PF & 0.97 & 0.93 & 0.98 & 5.3 & 3.6 & 7.0 & 98.3 \\
\hline & Net Force $_{100}$ & 0.83 & 0.64 & 0.92 & 18.5 & 11.7 & 25.4 & 86.0 \\
\hline & Net Force $_{150}$ & 0.88 & 0.75 & 0.95 & 13.7 & 8.8 & 18.5 & 104.3 \\
\hline & Net Force $_{200}$ & 0.95 & 0.89 & 0.98 & 7.5 & 4.8 & 10.2 & 75.1 \\
\hline & BW & 0.93 & 0.85 & 0.97 & 5.0 & 3.1 & 7.0 & 53.2 \\
\hline
\end{tabular}

Key: Hip ${ }_{145}$ : Hip joint angle $145^{\circ}$; Hip ${ }_{175}$ : Hip joint angle $175^{\circ}$; PF: Peak Force; RFD: Rate of force development; BW: Bodyweight; ICC:

Intraclass Correlation Coefficient; CV: Coefficient of Variation; Force ${ }_{100}$ : Force at $100 \mathrm{~ms}$; Force ${ }_{150}$ : Force at $150 \mathrm{~ms}$; Force 200 : Force at $200 \mathrm{~ms}$;

$\mathrm{RFD}_{100}$ : RFD 0-100 ms; RFD ${ }_{150}$ : RFD 0-150 ms; RFD 200 : RFD 0-200 ms; CI: Confidence interval; LB: Lower Bound; UB: Upper bound; Standard error of measurement 
Table 2. Between-session reliability measures of IMTP kinetics across postures $(\mathbf{n}=10)$

\begin{tabular}{|c|c|c|c|c|c|c|c|c|c|c|c|c|c|c|}
\hline & \multirow{2}{*}{ Variable } & \multicolumn{2}{|c|}{ Session 1} & \multicolumn{2}{|c|}{ Session 2} & \multirow{2}{*}{ ICC } & \multicolumn{2}{|c|}{$95 \% \mathrm{CI}$} & \multirow{2}{*}{ CV $(\%)$} & \multicolumn{2}{|c|}{$95 \% \mathrm{CI}$} & \multirow{2}{*}{ SEM } & \multirow{2}{*}{$p$} & \multirow{2}{*}{$g$} \\
\hline & & Mean & SD & MEAN & SD & & LB & UB & & $\mathbf{L B}$ & UB & & & \\
\hline \multirow{12}{*}{ Hip $_{145}$} & PF (N) & 2656.1 & 628.2 & 2518.9 & 643.6 & 0.97 & 0.81 & 0.99 & 4.5 & 1.6 & 7.3 & 110.2 & 0.033 & 0.21 \\
\hline & Force $_{100}(\mathrm{~N})$ & 1370.3 & 280.0 & 1381.3 & 267.2 & 0.84 & 0.33 & 0.96 & 8.0 & 3.6 & 12.5 & 109.5 & 0.872 & -0.04 \\
\hline & $\operatorname{RFD}_{100}(\mathbf{N} / \mathbf{s})$ & 5548.4 & 2552.3 & 5729.5 & 1802.2 & 0.85 & 0.36 & 0.96 & 15.2 & 9.4 & 21.1 & 867.0 & 0.740 & -0.08 \\
\hline & Force $_{150}(\mathrm{~N})$ & 1731.0 & 381.0 & 1690.8 & 394.3 & 0.90 & 0.61 & 0.98 & & 3.5 & 11.7 & 121.4 & 0.608 & 0.10 \\
\hline & $\operatorname{RFD}_{150}(\mathrm{~N} / \mathrm{s})$ & 6103.3 & 2314.0 & 5882.6 & 2176.8 & 0.91 & 0.64 & 0.98 & & 5.8 & 17.9 & 670.2 & 0.612 & 0.09 \\
\hline & Force $_{200}(\mathbf{N})$ & 1960.3 & 425.0 & 1883.7 & 437.3 & 0.94 & 0.77 & 0.99 & 6.6 & 4.0 & 9.1 & 106.5 & 0.264 & 0.17 \\
\hline & $\operatorname{RFD}_{200}(\mathrm{~N} / \mathrm{s})$ & 5724.1 & 1868.7 & 5376.4 & 1837.4 & 0.94 & 0.77 & 0.99 & 9.4 & 5.6 & 13.1 & 457.7 & 0.235 & 0.18 \\
\hline & Net PF (N) & 1883.5 & 577.5 & 1746.9 & 585.1 & 0.96 & 0.79 & 0.99 & 6.6 & 2.2 & 11.1 & 114.8 & 0.050 & 0.23 \\
\hline & Net Force $_{100}(\mathbf{N})$ & 597.7 & 253.0 & 609.3 & 180.9 & 0.85 & 0.36 & 0.96 & 12.8 & 7.2 & 18.4 & 86.0 & 0.830 & -0.05 \\
\hline & $\operatorname{Net}_{\text {Force }_{150}}(\mathrm{~N})$ & 958.3 & 344.1 & 918.8 & 325.3 & 0.91 & 0.65 & 0.98 & 9.9 & 4.5 & 15.2 & 100.5 & 0.542 & 0.11 \\
\hline & $\operatorname{Net}_{\text {Force }_{200}}(\mathbf{N})$ & 1187.7 & 371.0 & 1111.7 & 366.1 & 0.94 & 0.76 & 0.99 & 9.7 & 6.3 & 13.1 & 91.8 & 0.191 & 0.20 \\
\hline & BW $(\mathbf{N})$ & 772.6 & 121.6 & 772.0 & 143.9 & 0.97 & 0.86 & 0.99 & 4.0 & 2.5 & 5.4 & 24.5 & 0.970 & 0.00 \\
\hline \multirow{12}{*}{ Hip $_{175}$} & PF (N) & 2556.4 & 611.2 & 2531.8 & 574.6 & 0.97 & 0.89 & 0.99 & 5.3 & 3.0 & 7.6 & 101.0 & 0.716 & 0.04 \\
\hline & Force $_{100}(\mathrm{~N})$ & 1388.0 & 186.6 & 1339.7 & 262.4 & 0.88 & 0.55 & 0.97 & 5.2 & 0.1 & 10.3 & 78.5 & 0.33 & 0.20 \\
\hline & $\operatorname{RFD}_{100}(\mathrm{~N} / \mathrm{s})$ & 4484.1 & 1665.4 & 4247.9 & 1327.8 & 0.68 & -0.36 & 0.92 & 14.8 & 3.0 & 26.5 & 849.3 & 0.632 & 0.15 \\
\hline & Force $_{150}(\mathbf{N})$ & 1663.4 & 278.3 & 1593.2 & 339.0 & 0.93 & 0.73 & 0.98 & 5.1 & 0.7 & 9.5 & 82.1 & 0.175 & 0.22 \\
\hline & $\operatorname{RFD}_{150}(\mathrm{~N} / \mathrm{s})$ & 4825.7 & 1549.6 & 4521.9 & 1380.3 & 0.83 & 0.73 & 0.98 & 13.1 & 4.5 & 21.8 & 603.2 & 0.878 & 0.20 \\
\hline & Force $_{200}(\mathbf{N})$ & 1913.4 & 375.7 & 1839.3 & 390.2 & 0.95 & 0.80 & 0.99 & 5.3 & 1.7 & 9.0 & 86.5 & 0.181 & 0.19 \\
\hline & $\mathbf{R F D}_{200}(\mathrm{~N} / \mathbf{s})$ & 4869.4 & 1516.1 & 4621.9 & 1363.8 & 0.89 & 0.59 & 0.97 & 12.8 & 5.7 & 19.9 & 471.7 & 0.141 & 0.16 \\
\hline & Net PF (N) & 1660.46 & 551.72 & 1655.81 & 476.37 & 0.95 & 0.80 & 0.99 & 9.5 & 4.3 & 14.7 & 112.9 & 0.951 & 0.01 \\
\hline & Net $_{\text {Force }_{100}}(\mathbf{N})$ & 492.04 & 169.37 & 463.72 & 142.11 & 0.72 & -0.15 & 0.93 & 11.6 & 0.9 & 22.4 & 82.4 & 0.561 & 0.17 \\
\hline & Net Force $_{150}(\mathbf{N})$ & 767.48 & 236.99 & 717.21 & 212.07 & 0.85 & 0.43 & 0.96 & 11.0 & 3.0 & 19.0 & 87.4 & 0.355 & 0.21 \\
\hline & $\operatorname{Net}_{\text {Force }_{200}}(\mathbf{N})$ & 1017.52 & 307.14 & 963.32 & 275.49 & 0.89 & 0.608 & 0.974 & 11.9 & 5.7 & 18.0 & 93.6 & 0.364 & 0.18 \\
\hline & $\mathbf{B W}(\mathbf{N})$ & 895.9 & 167.5 & 876.0 & 158.6 & 0.97 & 0.88 & 0.99 & 3.2 & 1.2 & 5.3 & 29.6 & 0.3 & 0.12 \\
\hline
\end{tabular}

Key: Hip ${ }_{145}$ : Hip joint angle $145^{\circ}$; Hip ${ }_{175}$ : Hip joint angle $175^{\circ}$; PF: Peak Force; RFD: Rate of force development; BW: Bodyweight; ICC: Intraclass Correlation

Coefficient; CV: Coefficient of Variation; Force ${ }_{100}$ : Force at $100 \mathrm{~ms}$; Force ${ }_{150}$ : Force at $150 \mathrm{~ms}$; Force 200 : Force at $200 \mathrm{~ms}$; RFD Foo $_{100}$ RFD 0-100 ms; RFD F $_{150}$ RFD 0-150 ms; $\mathrm{RFD}_{200}$ : RFD 0-200 ms; CI: Confidence interval; LB: Lower Bound; UB: Upper bound; SEM: Standard error of measurement 
Table 3. Comparisons of IMTP kinetics between postures

\begin{tabular}{|c|c|c|c|c|c|c|c|c|c|c|c|}
\hline \multirow{3}{*}{$\frac{\text { Variable }}{\text { PF (N) }}$} & \multicolumn{2}{|c|}{ Hip $_{145}$} & \multicolumn{2}{|c|}{ Hip $_{175}$} & \multirow[b]{2}{*}{$p$} & \multirow[b]{2}{*}{$g$} & \multirow[b]{2}{*}{ Descriptor } & \multirow{2}{*}{\multicolumn{2}{|c|}{ Mean Difference (SD) }} & \multirow{2}{*}{\multicolumn{2}{|c|}{$\%$ Difference (SD) }} \\
\hline & \multirow{2}{*}{$\begin{array}{c}\text { MEAN } \\
2839.5\end{array}$} & \multirow{2}{*}{$\begin{array}{c}\text { SD } \\
677.7\end{array}$} & \multirow{2}{*}{$\begin{array}{c}\text { MEAN } \\
2747.2\end{array}$} & \multirow{2}{*}{$\begin{array}{c}\text { SD } \\
627.3\end{array}$} & & & & & & & \\
\hline & & & & & 0.066 & 0.14 & Trivial & 92.3 & $(255.4)$ & 2.6 & $(8.9)$ \\
\hline Force $_{100}(\mathrm{~N})$ & 1483.6 & 306.5 & 1488.2 & 284.9 & 0.893 & -0.02 & Trivial & -4.6 & $(179.0)$ & -1.3 & $(12.9)$ \\
\hline $\operatorname{RFD}_{100}(\mathbf{N} / \mathbf{s})$ & 6095.4 & 2516.5 & 4766.4 & 1908.0 & 0.001 & 0.59 & Small & 1329.0 & $(1821.0)$ & 16.8 & $(30.2)$ \\
\hline $\operatorname{Force}_{150}(\mathrm{~N})$ & 1900.8 & 416.4 & 1792.3 & 357.9 & 0.025 & 0.28 & Small & 108.5 & $(241.4)$ & 4.5 & $(13.1)$ \\
\hline $\operatorname{RFD}_{150}(\mathrm{~N} / \mathrm{s})$ & 6844.5 & 2426.4 & 5204.7 & 1639.9 & $<0.001$ & 0.78 & Moderat & & $(1710.1)$ & 21.1 & $(24.5)$ \\
\hline Force $_{200}(\mathbf{N})$ & 2125.5 & 442.2 & 2017.5 & 398.0 & 0.022 & 0.25 & Smal & 108.0 & $(234.2)$ & 4.4 & $(10.9)$ \\
\hline $\mathbf{R F D}_{200}(\mathrm{~N} / \mathrm{s})$ & 6257.0 & 1802.3 & 5029.4 & 1611.9 & $<0.001$ & 0.71 & Moderate & 1227.5 & (1318.2) & 18.5 & $(20.7)$ \\
\hline Net PF (N) & 2018.7 & 581.8 & 1791.5 & 524.4 & $<0.001$ & 0.40 & Small & 227.2 & $(298.4)$ & 10.4 & $(14.8)$ \\
\hline $\operatorname{Net}_{\text {Force }_{100}}(\mathbf{N})$ & 662.9 & 255.2 & 532.6 & 192.9 & 0.001 & 0.57 & Small & 130.3 & (189.3) & 14.4 & $(30.6)$ \\
\hline Net Force $_{150}(\mathrm{~N})$ & 1080.0 & 367.5 & 836.6 & 286.8 & $<0.001$ & 0.73 & Moderate & 243.4 & $(263.5)$ & 19.5 & $(24.0)$ \\
\hline $\operatorname{Net}_{\text {Force }_{200}}(\mathbf{N})$ & 1304.7 & 367.3 & 1061.8 & 320.8 & $<0.001$ & & Moderate & 242.9 & $(265.7)$ & 17.3 & $(19.4)$ \\
\hline BW $(\mathbf{N})$ & 820.8 & 157.7 & 955.7 & 201.3 & $<0.001$ & -0.74 & Moderate & -134.9 & $(71.5)$ & -16.2 & $(8.0)$ \\
\hline
\end{tabular}

Key: Hip $_{145}$ : Hip joint angle $145^{\circ}$; Hip ${ }_{175}$ : Hip joint angle $175^{\circ}$; PF: Peak Force; RFD; Rate of force development; BW: Bodyweight; Force ${ }_{100}$ : Force at 100 ms;

Force $_{150}$ : Force at $150 \mathrm{~ms}$; Force 200 : Force at $200 \mathrm{~ms}$; RFD ${ }_{100}$ : RFD 0-100 ms; RFD 150 : RFD 0-150 ms; RFD 200 : RFD 0-200 ms; 


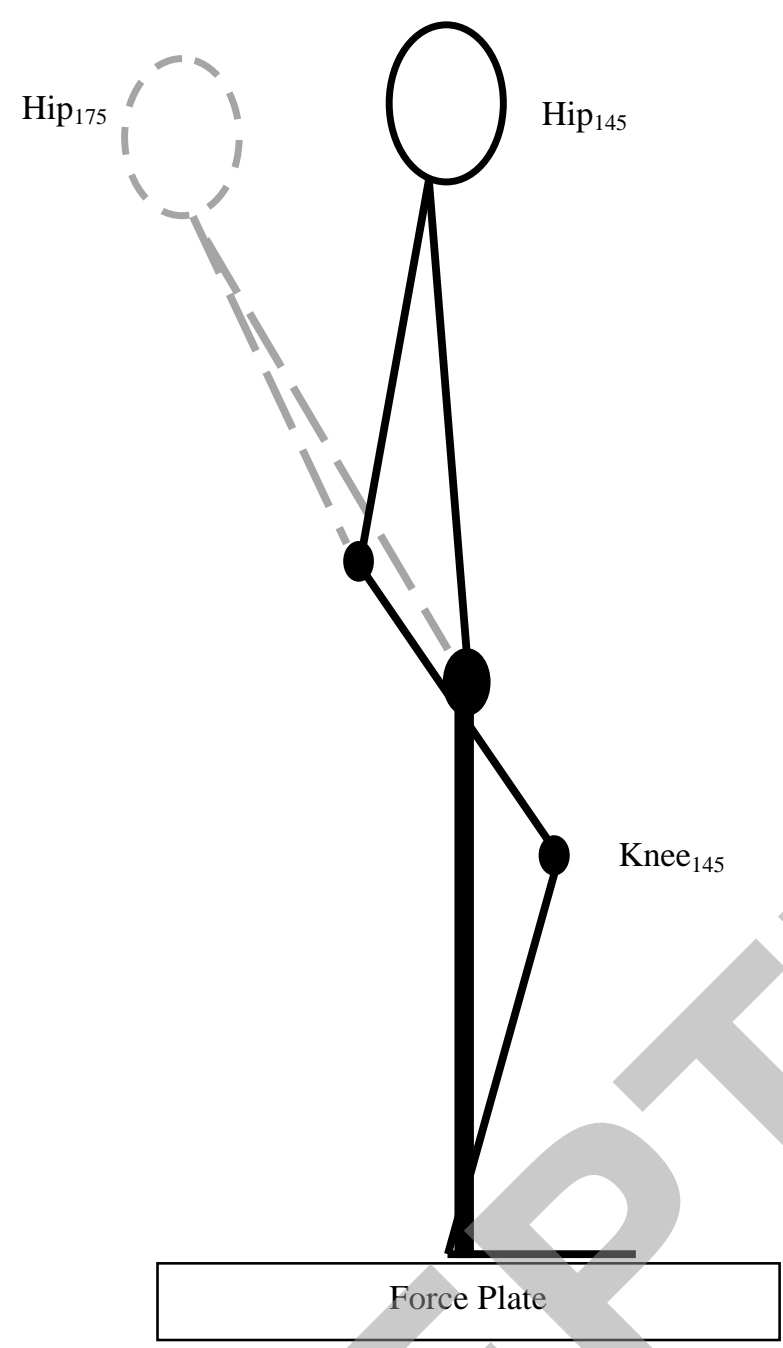

Figure 1. Schematic representation of IMTP positions with a standardised relative knee joint angle - Hip ${ }_{145}$ (solid black line) and Hip $_{175}$ (dashed grey line). 


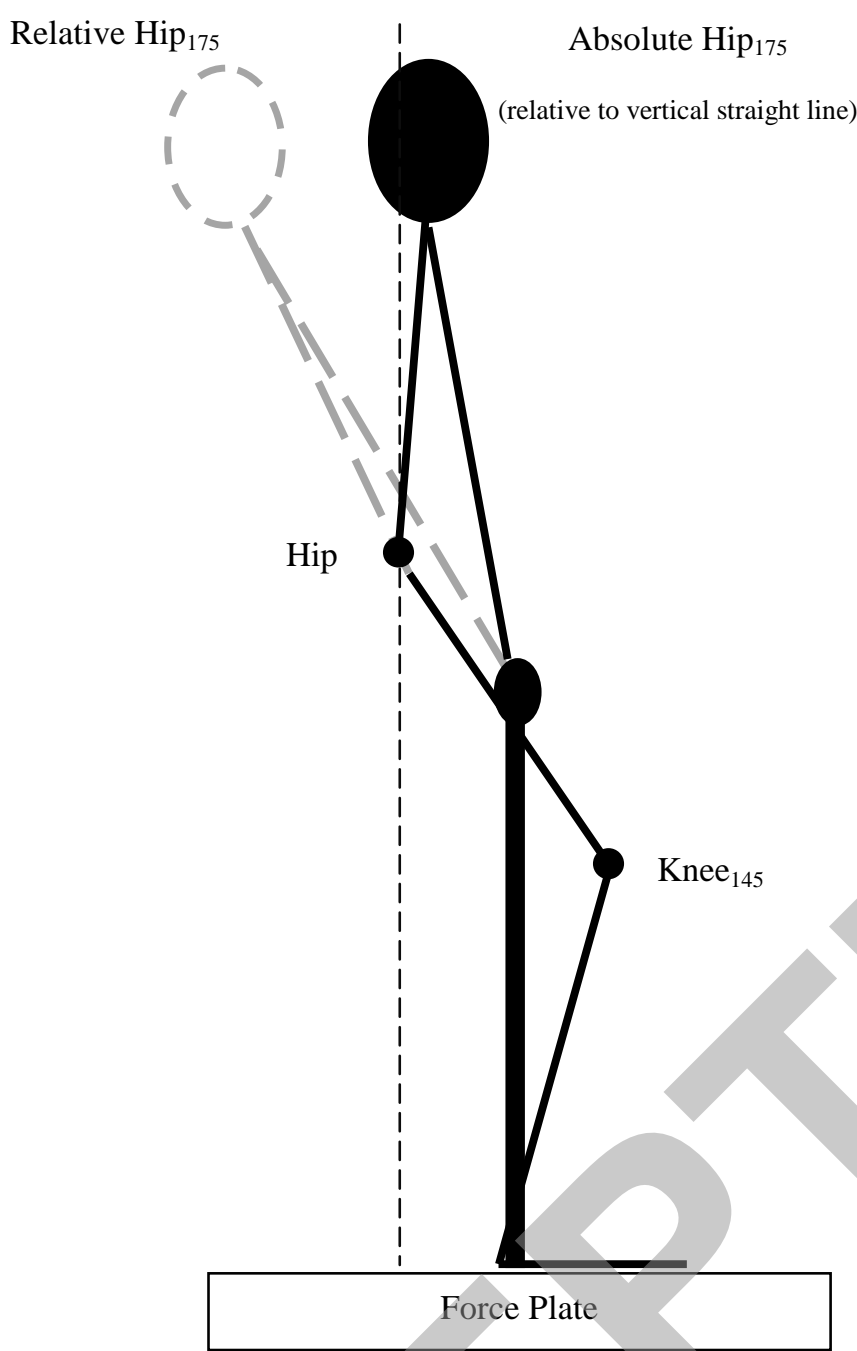

Figure 2. Schematic representation of relative and absolute $175^{\circ}$ hip joint angles IMTP positions with a standardised relative knee joint angle - Absolute (trunk) hip ${ }_{175}$ (solid black line) and Relative hip ${ }_{175}$ (dashed grey line). 